\title{
A simplified approach for determination of urinary ethyl glucuronide by gas chromatography-mass spectrometry
}

\author{
Shayani Ghosh, Raka Jain*, Satpal Singh, Ravindra Rao, Ashwani Kumar Mishra and Sonali Jhanjee
}

\begin{abstract}
Urinary ethyl glucuronide (EtG), an alcohol biomarker, plays an essential role in monitoring alcohol abstinence and relapse during treatment for alcohol dependence. Detection of this biomarker has become a routine in many clinical and forensic laboratories over the last few years. Most previously published methods commonly use hyphenated chromatographic techniques along with extensive extraction procedure before analysis. This work aimed to develop and validate an electron impact ionization mode gas chromatography-mass spectrometry method to measure ethyl glucuronide levels in human urine. For its determination, urine samples were dried under a gentle stream of nitrogen, derivatized with $\mathrm{N}, \mathrm{O}-\mathrm{bis}($ trimethylsilyl) trifluoroacetamide, incubated, and injected into the instrument. The analysis was performed using single quadrupole gas chromatography-mass spectrometry (GCMS) technology and validation was performed according to the guidelines of the German Society of Toxicology and Forensic Chemistry (GTFCh). The linearity of urinary EtG was obtained in the range of 30-5000 ng/ml with a correlation coefficient $(r)$ above 0.999 . The extraction recoveries exceeded $80 \%$, and the obtained inter-day and intra-day precisions were below 15\%. The achieved limit of detection was $10 \mathrm{ng} / \mathrm{ml}$ and limit of quantification achieved was $30 \mathrm{ng} / \mathrm{ml}$. The electron ionization gas chromatography-mass spectrometry technique proves to be a feasible option for determining EtG in human urine when other sophisticated techniques are unapproachable. This method provides a good sensitivity and proves to be cost-effective, robust, and advantageous for both clinical as well as forensic settings.
\end{abstract}

Keywords: Ethyl glucuronide, Gas chromatography-mass spectrometry, Urine, Ethanol metabolite, Validation, Precision, Accuracy

\section{Introduction}

Ethyl glucuronide (EtG) is a non-volatile, water-soluble, and stable direct metabolite of ethanol (Wurst et al. 2003). EtG has been used as a routine biomarker for monitoring alcohol abuse and abstinence. In humans, only a small fraction $(0.02-0.06 \%)$ of the total ethanol eliminated is bio transformed to EtG which can be detected in body fluids as well as hair (Crunelle et al. 2014; Washlam et al. 2012). Ethyl glucuronide was first

* Correspondence: rakajain2009@gmail.com

National Drug Dependence Treatment Centre, All India Institute of Medical Sciences, New Delhi 110029, India detected in human urine in 1967 by Jaakonmaki et al (Jaakonmaki et al. 1967). Urinary EtG is a useful diagnostic parameter for monitoring abstinence as well as relapse in patients with alcohol-dependence syndrome (Ghosh et al. 2019). It can be detected in urine for up to several days after elimination of alcohol; in some cases, it was found $80 \mathrm{~h}$ after heavy ethanol consumption (McDonell et al. 2015). Since 1967, a good number of studies were conducted to determine EtG, and its analysis has become routine in many clinical and forensic laboratories (Bicker et al. 2006; Rohrig et al. 2006; Weinmann et al. 2004; Wurst et al. 2003;). The most commonly used technique for detecting EtG in human urine 
is liquid chromatography (LC) coupled with electrospray tandem mass spectrometry (MS) (Bicker et al. 2006; Broucki et al. 2005). Although such analytical techniques are powerful and sensitive, not all laboratories have access to them. Also, various extraction procedures such as liquid-liquid extraction, solid-phase extraction (SPE), or solid-phase microextraction (Acikkol et al. 2015; Favretto et al. 2010; Freire et al. 2008; Janda and Alt 2001) have been employed for the detection of EtG to reduce matrix interference and improve detection. However, such extraction methods are cumbersome, timeconsuming, and expensive; they also have marginal extraction efficiency and require large amounts of organic solvents (Sharma et al. 2015). The lengthy extraction protocols and expensive high-resolution instruments demonstrate a need to explore an alternative and less labor-intensive approach. Gas chromatography-mass spectrometry (GC-MS) is a versatile technique that can measure a broad spectrum of primary water-soluble metabolites (Halket et al. 2005). Its strength is in measuring low-molecular-weight and volatile analytes, including small species that are typically not retained well in LC (Zimmermann et al. 2007). With simple derivatization, single quadrupole GC increases the stability of the metabolites and is cost-effective and robust (Halket et al. 2005).

The objective of this work was to develop a fast, sensitive, and reliable method to detect EtG in human urine using a standard benchtop GC-MS technology that is commonly available in laboratories. The method was validated and applied for the detection of EtG in urine of participants with alcohol dependence syndrome. The study protocol was reviewed and approved by the ethical committee of All India Institute of Medical Science, India.

\section{Methods}

\section{Chemicals and reagents}

EtG standard was obtained from Cerilliant (TX, USA), and the deuterated internal standard (IS) EtG-D $\mathrm{D}_{5}$ was purchased from TRC (Toronto, Canada). The derivatizing agent, N,O-bis(trimethylsilyl) trifluoroacetamide (BSTFA), was procured from Sigma-Aldrich (Missouri, USA). Methanol, acetone, and pyridine were obtained from Merck (Darmstadt, Germany). All chemicals were of highest analytical grade.

\section{Preparation of stock solution and urine specimens}

A stock solution of EtG $(10,000 \mathrm{ng} / \mathrm{ml})$ was made in methanol and stored at $-80{ }^{\circ} \mathrm{C}$. Standard working solutions was freshly prepared each day by dilution with methanol.

Urine sample $(30 \mathrm{ml})$ was collected from six adult volunteers who had no alcohol consumption history in the last 3 months. Each control urine sample was centrifuged at $5000 \mathrm{rpm}$ for $3 \mathrm{~min}$ and supernatant was decanted. After pooling the supernatant, a total of $100 \mathrm{ml}$ urine was separated. Ten milliliters of urine sample aliquots was prepared to avoid freeze and thaw cycle and was stored in clean and dry plastic containers. No preservative was used during urine sampling. All urine samples were stored at $-80^{\circ} \mathrm{C}$ until analysis.

\section{Standard preparation and derivatization}

After thawing, the aliquot control urine sample was centrifuged at $5000 \mathrm{rpm}$. One hundred microlitres of urine sample was taken and appropriate volumes of standard EtG solution were added to the blank urine, resulting in final concentration of 5000, 1000, 500, 250, 100, 50 and $30 \mathrm{ng} / \mathrm{ml}$. Then $50 \mu \mathrm{l}$ of EtG-D $(250 \mathrm{ng} / \mathrm{ml})$ was added as an IS before adding methanol to a total volume of 1 $\mathrm{ml}$. Prepared samples were vortexed for $2 \mathrm{~min}$ and evaporated to dryness for 20 min under a gentle stream of nitrogen. The dried residue was derivatized with $50 \mu \mathrm{l}$ of BSTFA and $50 \mu \mathrm{l}$ of pyridine. The tubes were tightly closed, vortexed (10 s), and incubated in a hot air oven at $100^{\circ} \mathrm{C}$ for $30 \mathrm{~min}$. After cooling the solution at room temperature, $2 \mu \mathrm{l}$ of extract was injected into the GCMS instrument.

\section{Gas chromatography-mass spectrometry conditions}

Analysis of EtG was performed in an EI-GC-MS system comprising a gas chromatograph (7890B series, Agilent) equipped with an automatic injector and coupled with a mass spectrometer (5977B). Chromatographic separation was achieved on an Agilent DB-5 fused silica capillary column (30 $\mathrm{m} \times 0.25 \mathrm{~mm}$ ID, $0.25 \mu \mathrm{m}$ film thickness). The carrier gas was helium at a constant flow rate of $1 \mathrm{ml} / \mathrm{min}$. Samples $(2 \mu \mathrm{l})$ were injected in splitless mode at an injection temperature of $250^{\circ} \mathrm{C}$. The oven temperature was maintained at $100^{\circ} \mathrm{C}$ for $2 \mathrm{~min}$, increased at $10^{\circ} \mathrm{C} / \mathrm{min}$ to $250^{\circ} \mathrm{C}$, maintained constant for $2 \mathrm{~min}$, increased again at $15^{\circ} \mathrm{C} / \mathrm{min}$ to $300^{\circ} \mathrm{C}$, and held for $1 \mathrm{~min}$. The total run time was $22 \mathrm{~min}$. The mass detector was operated at $70 \mathrm{eV}$ in the EI ionization mode. The ion source was maintained at $230^{\circ} \mathrm{C}$. The data was acquired in the selected-ion monitoring (SIM) mode. Quantifier and qualifier ions for each analyte were selected based on their abundance and $\mathrm{m} / \mathrm{z}$ values. The observed trimethylsilyl (TMS) derivative ions were identified for EtG at $m / z$ : 160, 261 (quantifier), and 405, and for EtG-D $\mathrm{D}_{5}$ at $m / z: 165,266$ (quantifier), and 410.

\section{Method validation}

The analytical method was validated in accordance to guidelines of the German Society of Toxicology and Forensic Chemistry (GTFCh), keeping in view selectivity of the method, linearity, bias, precision, accuracy, recovery, limit of detection (LOD), and limit of quantitation (LOQ) (Peters et al. 2009). 
The calibration curve was made by adding defined volumes of methanolic solution of the reference standards of EtG to control urine sample. Spiked quality-control samples were prepared in five replicates at seven concentration levels and $250 \mathrm{ng} / \mathrm{mL}$ of internal standard (EtG- $\mathrm{D}_{5}$ ) was added. The concentrations of calibration standard were 5000, 1,000, 500, 250, 100, 50, and $30 \mathrm{ng} / \mathrm{ml}$.

In this work, bias was obtained as the deviation of the average test result and the actual reference value, thereby giving a measure of the systematic errors; accuracy was obtained as the percentage deviation of each test result and the actual reference value. On the other hand, precision was acquired as the degree of scatter within a set of measurements and was a measure of the random errors. Intra-assay or repeatability expressed the precision under the same operating conditions over a short time interval. Inter-assay, on the other hand, showed the precision between runs and from day to day. The interbatch and intra-batch coefficient variation to determine precision of the method had to be $\leq 15 \%$ (20\% near the limit of quantification). Repeatability was determined in multiple measurements of the samples under the same analytical conditions.

The recovery was calculated by comparing the peak areas of the urine spiked standards with peak areas of direct neat standards in methanol. Acceptable specificity was defined as the capability of the method to detect and identify the target component (EtG) in the spiked urine samples without any interference.

The LOD was defined as the lowest concentration of the analyte in the urine matrix that can be identified and reported. It was calculated using a single quantifier ion with a signal-to-noise ratio greater than 3 . The LOQ of the method was defined as the lowest concentration of the analyte in the urine matrix that can be measured, reported, and determined with an acceptable precision (RSD $\leq 20 \%$ ). It was calculated using a single quantifier ion with a signal-to-noise ratio greater than 10 . The LOD and LOQ were estimated according to DIN 32645 (Peters et al. 2009).

\section{Results}

\section{Selectivity}

Six blank urine samples and two zero samples (blanks with internal standard, IS) were tested to ensure no interferences. The retention time (RT) of EtG and EtG- $\mathrm{D}_{5}$ (IS) were 16.80 and $16.75 \mathrm{~min}$, respectively. As it can be seen in Fig. 1 from the chromatograms obtained for a blank urine sample and a sample spiked with $5000 \mathrm{ng} /$ mg EtG, no interfering signals were observed in the analyte's and IS's retention time window. Figure 2 shows the TMS derivative ions for EtG- $\mathrm{D}_{5}$ were at $m / z: 165$, 266 (quantifier), and 410, and those for EtG were at $\mathrm{m} / z$ : 160, 261 (quantifier), and 405.

\section{Linearity}

Five calibrators were prepared by spiking blank urine matrix with definite concentration of $\mathrm{EtG}$ at five different concentration levels $(5000-30 \mathrm{ng} / \mathrm{ml})$. Linearity was verified with the Mandel-F-test at the $99 \%$ significance level, after ensuring homogeneity of the variances across the calibration range and the absence of straggler and

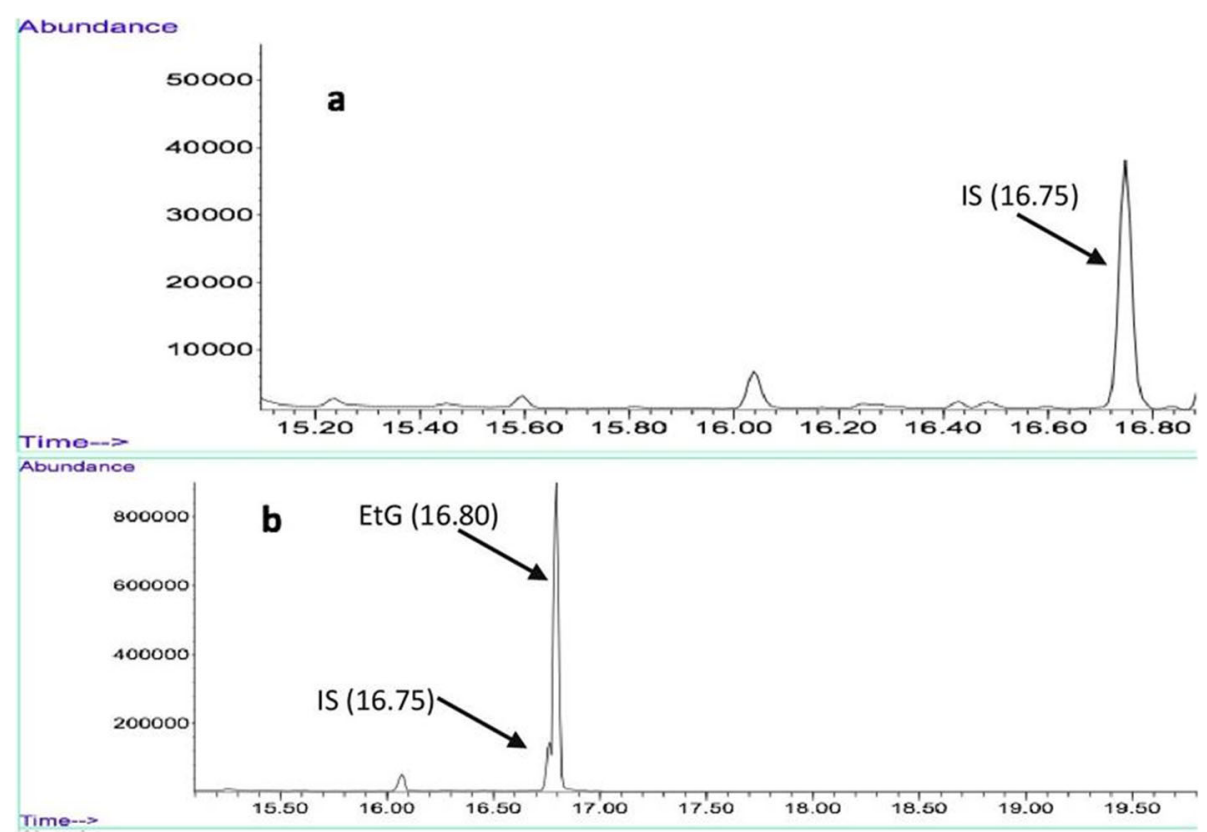

Fig. 1 a Chromatogram of blank urine with IS (500 ng/ml). b Chromatogram of urine spiked with EtG (5000 ng/ml) and IS (250ng/ml) 


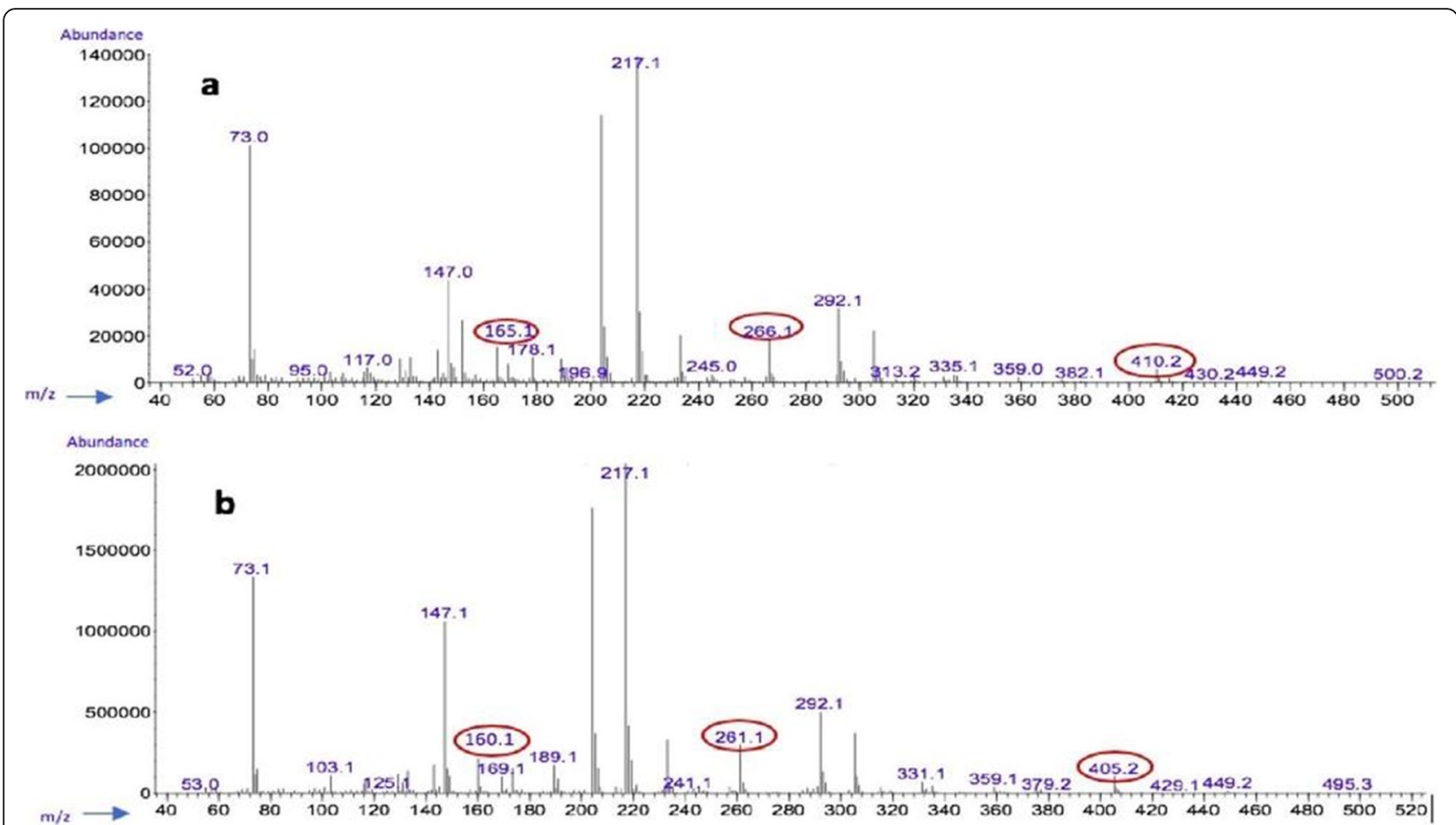

Fig. 2 a Mass fragmentation pattern of tri-methylsilyl derivatives of EtG- $\mathrm{D}_{5}$ (IS). b Mass fragmentation pattern of tri-methylsilyl derivatives of EtG

outliers by means of the Grubbs-test at $99 \%$ significance level respectively as given in DIN 32645 (Peters et al. 2009).

A total of six replicates for all the calibrators $(5000$, $1,000,500,250,100,50$, and $30 \mathrm{ng} / \mathrm{ml}$ ) were analyzed and were found to be homogenous, free of straggler, and outliers. A good linearity was obtained with a slope of 0.96 and a correlation coefficient above 0.999 in the range from 30 to $5000 \mathrm{ng} / \mathrm{ml}$ urine as shown in Table 1.

\section{Bias, accuracy, and precision}

Bias was expressed in percentage and calculated from the average of all measurements and the accepted reference value at three different concentrations (30, 250, $5000 \mathrm{ng} / \mathrm{ml}$ ) along the linearity range. The obtained values were within $\pm 15 \%( \pm 20 \%$ near the limit of quantification) and were in accordance with the acceptance criteria of the German Society of Toxicological and

Table 1 Response function for EtG in urine at 99\% confidence intervals

\begin{tabular}{ll}
\hline Concentration range $\mathbf{( n g} / \mathbf{m l})$ & $\mathbf{3 0 - 5 0 0 0}$ \\
\hline Slope & $0.96 \pm 0.01$ \\
Intercept & $0.5 \pm 0.1$ \\
$R^{2}$ & 0.9998 \\
F-Test for outlier's (99\%) & Passed \\
Mandel-Test for linearity (99\%) & Passed \\
\hline
\end{tabular}

Forensic Chemistry (GTFCh) as shown in Table 2 (Peters et al. 2009). Accuracy was determined by spiking blank samples with EtG $(n=6)$ at three different concentrations on three consecutive days, and the accuracy was expressed as the percentage of the obtained concentration divided by the expected spiked concentration. The obtained accuracy of the method at the three concentrations, 30, 250, and 5,000 $\mathrm{ng} / \mathrm{ml}$, was $91.11 \%$, $96.60 \%$, and $92.86 \%$, respectively. Intra and inter-day assay precisions were expressed as the relative standard deviation (RSD) and was determined at three controlled concentrations: 30,250 , and $5000 \mathrm{ng} / \mathrm{ml}$. The intra-day precision was determined by assaying six replicates of the urine matrix at three concentrations on the same day. Similarly, the inter-day precision was calculated for

Table 2 Validation data for bias, precision, and accuracy

\begin{tabular}{lllll}
\hline Concentrations $\mathbf{( n g / m l )}$ & & $\mathbf{3 0}$ & $\mathbf{2 5 0}$ & $\mathbf{5 0 0 0}$ \\
\hline Intra-day Precision & Average & 26.8 & 244.7 & 4790 \\
& SD & 1.2 & 3.9 & 190.4 \\
& RSD (\%) & 4.4 & 1.6 & 4 \\
Inter-day Precision & Average & 27.3 & 241.5 & 4643 \\
& SD & 1.5 & 4.9 & 316.4 \\
Accuracy (\%) & RSD (\%) & 5.5 & 2.0 & 6.8 \\
Bias (\%) & & 91 & 97 & 93 \\
\hline
\end{tabular}




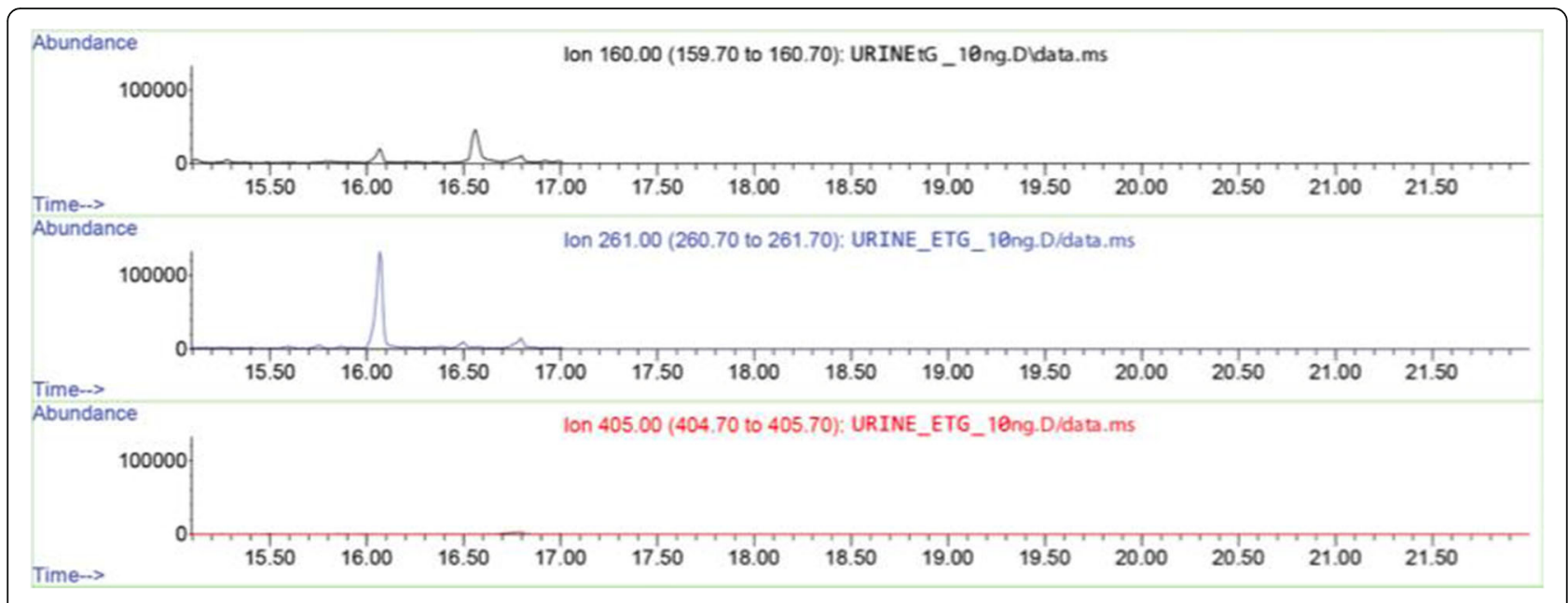

Fig. 3 Reconstructed ion chromatogram of $10 \mathrm{ng} / \mathrm{ml}$ (LOD)

six replicates at three different concentrations for three consecutive days. The obtained values for both intra-day and inter-day precision are shown in Table 2.

\section{Recovery}

The recovery was determined by comparing the peak areas of the extracted standards with those of neat standards $(n=6)$ at three different concentrations: 30, 250, and 5,000 $\mathrm{ng} / \mathrm{ml}$. The percentage EtG recoveries at these concentrations were $85 \pm 1.8,83 \pm 2.3$, and $80 \pm 3.5$, respectively.

\section{Limit of detection and limit of quantification}

For LOD, three replicates of urine matrix spiked with lowest concentration $(10 \mathrm{ng} / \mathrm{ml})$ of EtG were examined for three consecutive days. A signal-to-noise ratio of 3.9 was obtained at $10 \mathrm{ng} / \mathrm{ml}$ and the reconstructed ion chromatogram (RIC) of the same is shown in Fig. 3.
Simultaneously, for LOQ, three replicates of urine matrix spiked with the expected concentration (30ng/ $\mathrm{ml}$ ) of EtG were examined for three consecutive days. A signal-to-noise ratio of 10.6 was obtained at $30 \mathrm{ng} / \mathrm{ml}$ and the RIC of the same is shown in Fig. 4.

\section{Application of the method}

The applicability of the developed method was examined on urine specimen of ten patients with alcohol dependence syndrome seeking treatment from a tertiary deaddiction center in northern India. The recruited patients were diagnosed with alcohol dependence syndrome as per the International Classification of Diseases, Version-10 with alcohol consumption within the last 24 h. For every urine sample obtained, a breath alcohol measurement was performed in parallel and the time since the last alcohol consumed was recorded. Breath ethanol measurements were performed using AlcoMate

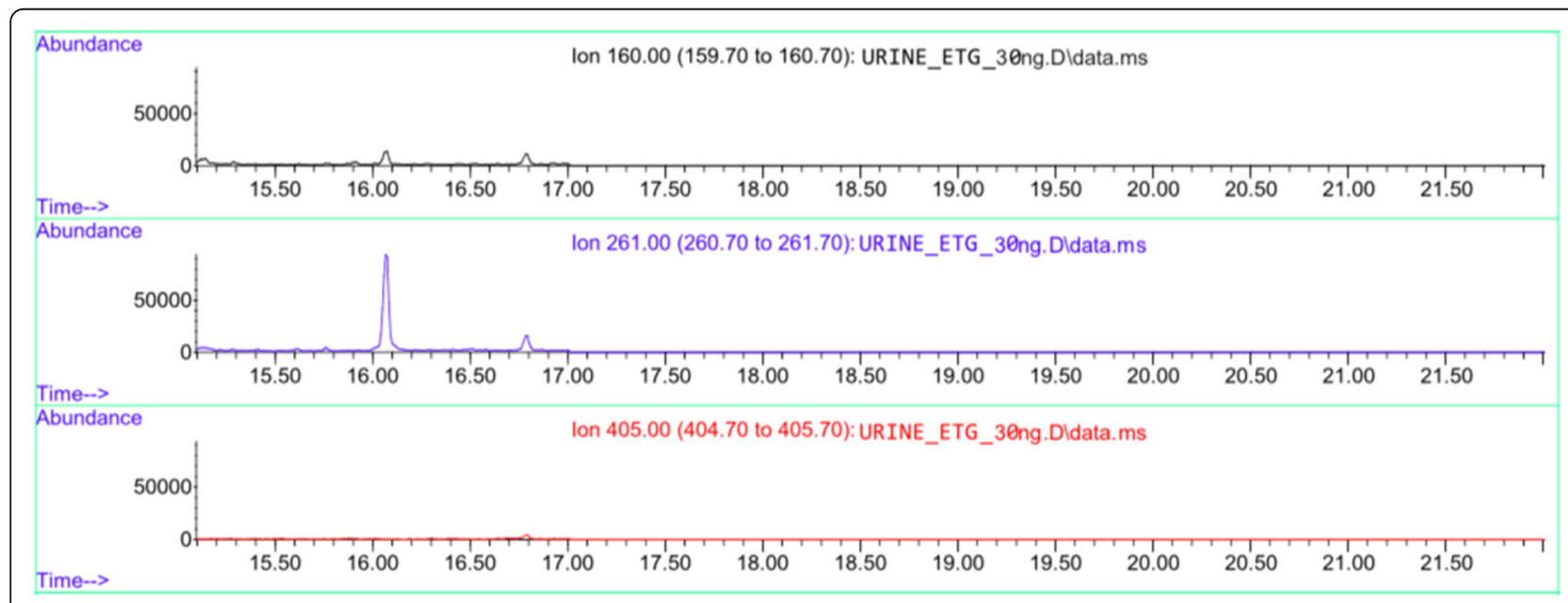

Fig. 4 Reconstructed ion chromatogram of $30 \mathrm{ng} / \mathrm{ml}$ (LOQ) 
Table 3 Analyzed urine samples and their breath test values

\begin{tabular}{llll}
\hline Sample number & Hours since last alcohol consumed & BAC (\%) & Urine EtG (ng/ml) \\
\hline A1 & 07 & 0.40 & 7061.59 \\
A2 & 06 & 0.35 & $59,432.56$ \\
A3 & 06 & 0.40 & $83,329.86$ \\
A4 & 06 & 0.40 & 6322.72 \\
A5 & 08 & 0.40 & 547.67 \\
A6 & 09 & 0.40 & 44.88 \\
A7 & 12 & 0.10 & 8764.54 \\
A8 & 09 & 0.40 & $78,943.44$ \\
A9 & 06 & 0.23 & $79,177.76$ \\
A10 & 04 & 0.40 & $56,990.33$ \\
\hline
\end{tabular}

Premium (Model AL7000) alcohol tester, and the results were expressed as the corresponding blood alcohol concentration (BAC; range $0.000-0.400 \%$ ). All samples were analyzed as real routine samples and the results are shown in Table 3. Figure $5(83,329 \mathrm{ng} / \mathrm{ml})$ and Fig. 6 $(45 \mathrm{ng} / \mathrm{ml})$ shows the chromatogram of two patient's urine sample showing presence of EtG.

\section{Discussion}

Ethyl glucuronide has proven to be a reliable biomarker for monitoring alcohol consumption and relapse
(Washlam et al. 2014). It has been successfully used in both clinical and medicolegal toxicology (Santunione et al. 2018). Although several studies have been published on determining EtG levels in urine, most of them employed highly sophisticated and expensive techniques like LC-MS or LC-MS-MS (Helander et al. 2010). Even with such hyphenated techniques becoming popular, some laboratories still have access only to EI-GC-MS instrumentation. This study discusses a fast and reliable GC-MS method with optimized chromatographic separation for the quantitation of EtG in urine using a DB-5

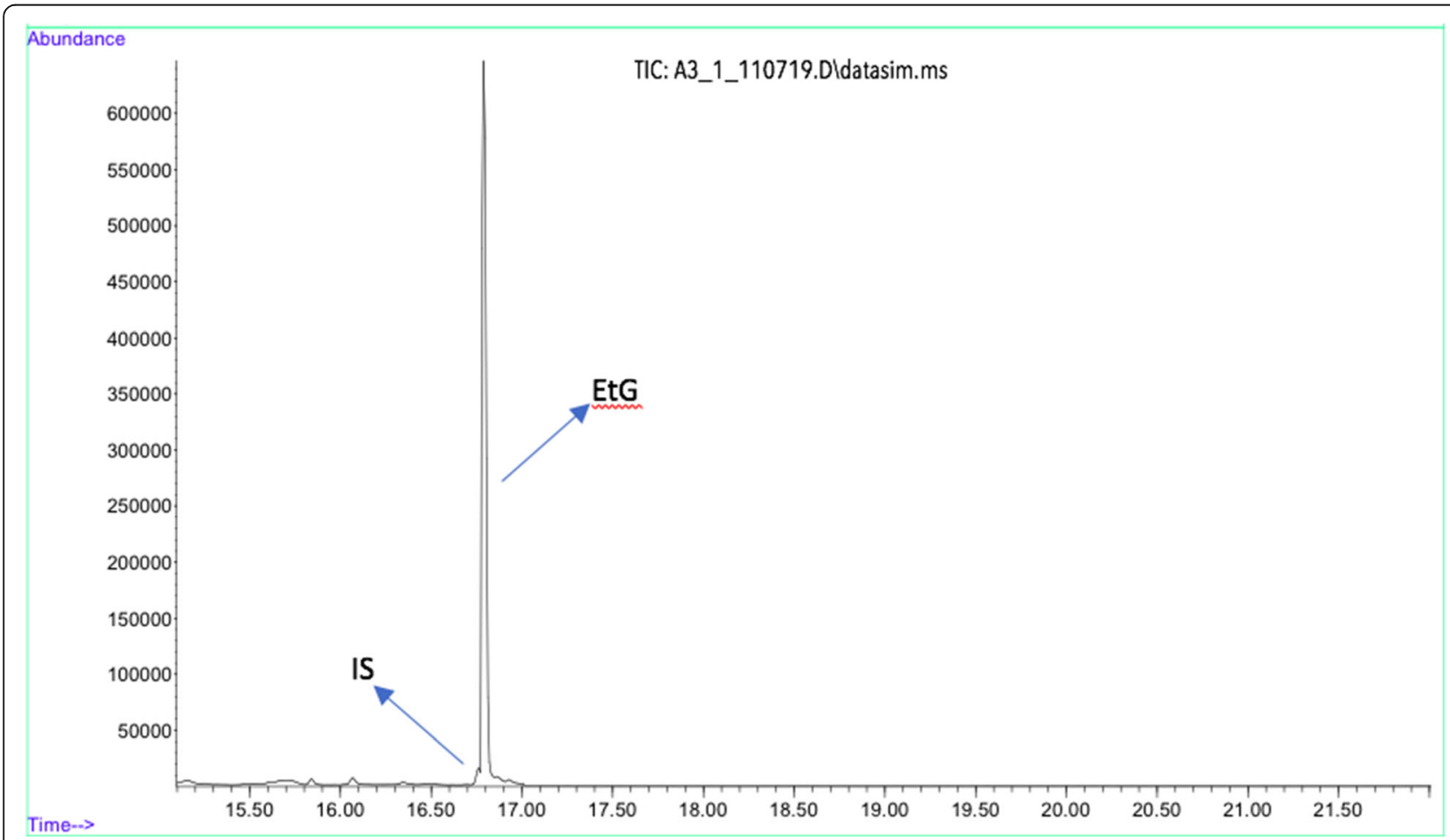

Fig. 5 Chromatogram of a patient's urine showing presence of EtG $(83,329 \mathrm{ng} / \mathrm{ml})$ 


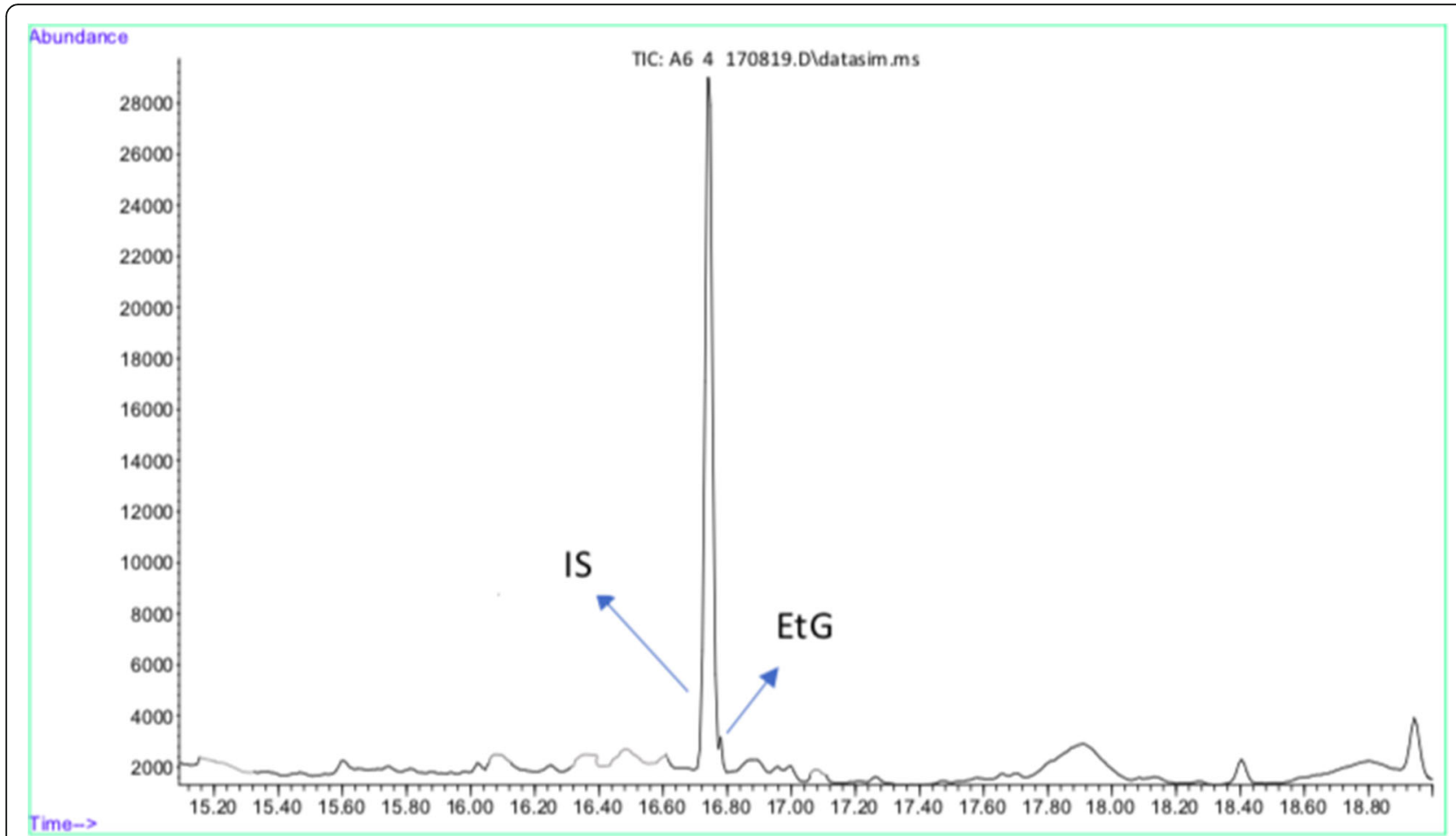

Fig. 6 Chromatogram of a patient's urine showing presence of EtG $(45 \mathrm{ng} / \mathrm{ml})$

fused silica capillary column. The calibration curve ranged between 30 and $5000 \mathrm{ng} / \mathrm{ml}$. Additionally, analysis of metabolites in biological matrices often involves certain complex extraction methods (Zheng et al. 2008) However, the present method did not employ any sample pre-treatment technique and obtained a good LOQ (30 $\mathrm{ng} / \mathrm{ml})$ and LOD $(10 \mathrm{ng} / \mathrm{ml})$. The LOQ achieved by this method indicated a higher sensitivity than in other studies, where conventional extraction techniques were used with sensitive analytical instruments; comparisons are briefly shown in Table 4. Bias, precision, and accuracy obtained fulfill the validation requirements. This method has been successfully used in our laboratory to analyze EtG in the urine of patients with alcohol dependence syndrome. The developed procedure will be advantageous in analyzing EtG in de-addiction or medico-legal cases for the detection and monitoring of alcohol consumption.

\section{Conclusion}

A validated simple and reproducible GC-MS method which fulfills the requirements for confirmatory and quantitative analysis of EtG in urine has been discussed in this study. The step by step method validation has been performed according to guidelines of the GTFCh and general rules for bioanalytical method validation (Peters et al. 2009). The method was observed to be advantageous and sensitive as compared

Table 4 A comparison of the LOD, LOQ, extraction techniques, and instruments used in our study and other published methods

\begin{tabular}{|c|c|c|c|c|c|c|c|c|}
\hline $\begin{array}{l}\text { Urine } \\
\text { matrix }\end{array}$ & $\begin{array}{l}\text { Our } \\
\text { results }\end{array}$ & Freire et al. 2008 & $\begin{array}{l}\text { Janda and } \\
\text { Alt } 2001\end{array}$ & $\begin{array}{l}\text { Sharma et al. } \\
2015\end{array}$ & $\begin{array}{l}\text { Favretto } \\
\text { et al. } 2010\end{array}$ & Shah and Lacourse 2006 & $\begin{array}{l}\text { Beyer } \\
\text { et al. } 2011\end{array}$ & $\begin{array}{l}\text { Broucki et al. } \\
2005\end{array}$ \\
\hline $\begin{array}{l}\text { Extraction } \\
\text { technique }\end{array}$ & None & $\begin{array}{l}\text { Microwave-assisted } \\
\text { extraction }\end{array}$ & $\begin{array}{l}\text { Solid-phase } \\
\text { extraction }\end{array}$ & $\begin{array}{l}\text { Solid-phase } \\
\text { extraction }\end{array}$ & $\begin{array}{l}\text { Solid-phase } \\
\text { extraction }\end{array}$ & Solid-phase extraction & None & $\begin{array}{l}\text { Cation- } \\
\text { exchange } \\
\text { resin }\end{array}$ \\
\hline Method & GC-MS & GC-MS & GC-MS & GC-MS & LC-MS & $\begin{array}{l}\text { LC with pulsed } \\
\text { electrochemical detection }\end{array}$ & LC-MS/MS & LC-MS/MS \\
\hline LOD (ng/ml) & 10 & 5 & 168 & 50 & 5 & 80 & 100 & Unknown \\
\hline LOQ (ng/ml) & 30 & 100 & 560 & 150 & 100 & 370 & 100 & 100 \\
\hline
\end{tabular}


to other discussed methods for analyses of EtG in urine. One of the advantages of the developed method is the achieved LOQ, which yet has not been achieved by any other hyphenated chromatographic technique. Furthermore, it is cost-effective and requires no cumbersome extraction protocols. It is a viable option for analyzing EtG in laboratories that have access to standard benchtop EI-GC-MS technology.

\section{Abbreviations \\ BAC: Blood alcohol concentration; BSTFA: N, O-Bis(trimethylsilyl) Trifluoroace- tamide; El-GC-MS: Electron ionization-gas chromatogrpahy-mass spectrom- etry; EtG: Ethyl glucuronide; GTFCh: German Society of Toxicology and Forensic Chemistry; IS: Internal standard; LOD: Limit of detection; LOQ: Limit of quantitation; LC: Liquid chromatography; LC-MS-MS: Liquid chromatography tandem mass spectrometry; RIC: Reconstructed ion chromatogram; RSD: Relative standard deviation; RT: Retention time; SIM: Single ion monitoring; SPE: Solid phase extraction; TMS: Trimethylsilyl derivative ions}

\section{Acknowledgements}

This work was supported by National Drug Dependence Treatment Centre, All India Institute of Medical Sciences, New Delhi, MOH \& FW, Government of India, and University Grants Commission (UGC) Government of India.

\section{Authors' contributions}

RJ and SG contributed to the design of the study. SG performed the experiments. SS assisted in analyzing the data. RJ, RR, SJ, and AKM gave their valuable suggestions during the course of validation. SG wrote the manuscript. All authors read and approved the final manuscript.

\section{Funding}

None

Availability of data and materials

Not applicable

\section{Declarations}

\section{Ethics approval and consent to participate}

This study was approved by the institute ethics committee. Informed consent has been obtained from the participating individuals.

\section{Consent for publication}

The authors have no objection regarding publication of the article

\section{Competing interests}

The authors declare that they have no competing interests.

Received: 13 May 2021 Accepted: 28 July 2021

Published online: 11 August 2021

\section{References}

Acikkol M, Ozdemir AA, Anilanmert B, Mirsal H. A highly specific, fully validated urinary ethyl glucuronide analysis using solid phase extraction-liquid chromatography/electrospray ionization-tandem mass spectrometry. J AOAC Int. 2015;98(3):760-6. https://doi.org/10.5740/jaoacint.14-094.

Beyer J, Vo TN, Gerostamoulos D, Drummer OH. Validated method for the determination of ethylglucuronide and ethylsulfate in human urine. Anal Bioanal Chem. 2011;400(1):189-96. https://doi.org/10.1007/s00216-011-4667-2.

Bicker W, Lämmerhofer M, Keller T, Schuhmacher R, Krska R, Lindner W. Validated method for the determination of the ethanol consumption markers ethyl glucuronide, ethyl phosphate, and ethyl sulfate in human urine by reversedphase/weak anion exchange liquid chromatography-tandem mass spectrometry. Anal Chem. 2006;78(16):5884-92. https://doi.org/10.1021/a c060680+.

Borucki K, Schreiner R, Dierkes J, Jachau K, Krause D, Westphal S, et al. Detection of recent ethanol intake with new markers: comparison of fatty acid ethyl esters in serum and of ethyl glucuronide and the ratio of 5-hydroxytryptophol to 5-hydroxyindole acetic acid in urine. Alcohol Clin Exp Res. 2005;29(5):781-7. https://doi.org/10.1097/01.alc.0000164372. 67018.ea.

Crunelle CL, Yegles M, Nuijs ALNV, Covaci A, De Doncker M, Maudens KE, et al. Hair ethyl glucuronide levels as a marker for alcohol use and abuse: a review of the current state of the art. Drug Alcohol Depend. 2014;1(134):1-11. https://doi.org/10.1016/j.drugalcdep.2013.10.008.

Favretto D, Nalesso A, Frison G, Viel G, Traldi P, Ferrara SD. A novel and an effective analytical approach for the LC-MS determination of ethyl glucuronide and ethyl sulfate in urine. Int J Legal Med. 2010;124(2):161-4. https://doi.org/10.1007/s00414-009-0376-1.

Freire IA, Barrera AM, Silva PC, Duque MJ, Gómez PF, Eijo PL. Microwave assisted extraction for the determination of ethyl glucuronide in urine by gas chromatography-mass spectrometry. J Appl Toxicol. 2008;28(6):773-8. https:// doi.org/10.1002/jat.1338.

Ghosh S, Jain R, Jhanjee S, Rao R, Mishra A. Alcohol biomarkers and their relevance in detection of alcohol consumption in clinical settings. Int Arch Subst Abuse Rehabil. 2019;1(002). https://doi.org/10.23937/iasar-201 7/1710002.

Halket JM, Waterman D, Przyborowska AM, Patel RK, Fraser PD, Bramley PM. Chemical derivatization and mass spectral libraries in metabolic profiling by GC/MS and LC/MS/MS. J Exp Bot. 2005;56(410):219-43. https://doi.org/10.1 093/jxb/erio69.

Helander A, Kenan N, Beck O. Comparison of analytical approaches for liquid chromatography/mass spectrometry determination of the alcohol biomarker ethyl glucuronide in urine. Rapid Commun Mass Spectrom. 2010;24(12): 1737-43. https://doi.org/10.1002/rcm.4573.

Jaakonmaki PI, Knox KL, Horning EC, Horning MG. The characterization by gasliquid chromatography of ethyll beta-D-glucosiduronic acid as a metabolite of ethanol in rat and man. Eur J Pharmacol. 1967;1(1):63-70. https://doi.org/1 $0.1016 / 0014-2999(67) 90067-2$

Janda I, Alt A. Improvement of ethyl glucuronide determination in human urine and serum samples by solid-phase extraction. J Chromatogr B Biomed Sci Appl. 2001;758(2):229-34. https://doi.org/10.1016/s0378-4347(01)00186-4.

McDonell MG, Skalisky J, Leickly E, McPherson S, Battalio S, Nepom JR, et al. Using ethyl glucuronide in urine to detect light and heavy drinking in alcohol dependent outpatients. Drug Alcohol Depend. 2015;157:184-7. https://doi. org/10.1016/j.drugalcdep.2015.10.004.

Peters FT, Hartung M, Herbold M, Schmitt G, Daldrup T, Mushoff F, et al. Richtlinie der GTFCh zur Qualitätssicherung bei forensisch-toxikologischen Untersuchungen. [Appendix B to the guidelines of GTFCh for quality assurance in forensic-toxicological investigations]. Anforderungen an die Validierung von Analysenmethoden. 2009;76(3):185-208.

Rohrig TP, Huber C, Goodson L, Ross W. Detection of ethyl glucuronide in urine following the application of Germ-X. J Anal Toxicol. 2006;30(9):703-4. https:// doi.org/10.1093/jat/30.9.703.

Santunione AL, Verri P, Marchesi F, Rustichelli C, Palazzoli F, Vandelli D, et al. The role of ethyl glucuronide in supporting medico-legal investigations: Analysis of this biomarker in different postmortem specimens from 21 selected autopsy cases. J Forensic Legal Med. 2018;53:25-30. https://doi.org/10.1016/j. jflm.2017.10.009.

Shah $R$, Lacourse WR. An improved method to detect ethyl glucuronide in urine using reversed-phase liquid chromatography and pulsed electrochemical detection. Anal Chim Acta. 2006;576(2):239-45. https://doi.org/10.1016/j.aca.2 006.06.017.

Sharma P, Bharat V, Murthy P. Quantitation of ethyl glucuronide in serum and urine by gas chromatography - mass spectrometry. Indian J Med Res. 2015; 141(1):75-80. https://doi.org/10.4103/0971-5916.154507.

Walsham NE, Sherwood RA. Ethyl glucuronide. Ann Clin Biochem. 2012;49(2):1107. https://doi.org/10.1258/acb.2011.011115.

Walsham NE, Sherwood RA. Ethyl glucuronide and ethyl sulfate. Adv Clin Chem. 2014;67:47-71. https://doi.org/10.1016/bs.acc.2014.09.006.

Weinmann W, Schaefer P, Thierauf A, Schreiber A, Wurst FM. Confirmatory analysis of ethyl glucuronide in urine by liquid-chromatography/electrospray ionization/tandem mass spectrometry according to forensic guidelines. J Am Soc Mass Spectrom. 2004;15(2):188-93. https://doi.org/10.1016/j.jasms.2003.1 0.010 .

Wurst FM, Skipper GE, Weinmann W. Ethyl glucuronide -the direct ethanol metabolite on the threshold from science to routine use. Addiction. 2003; 98(Suppl 2):51-61. https://doi.org/10.1046/j.1359-6357.2003.00588.x. 
Zheng Y, Helander A. Solid-phase extraction procedure for ethyl glucuronide in urine. J Anal Toxicol. 2008;32(9):778-81. https://doi.org/10.1093/jat/32.9.778.

Zimmermann D, Hartmann M, Moyer MP, Nolte J, Baumbach JI. Determination of volatile products of human colon cell line metabolism by GC/MS analysis. Metabolomics. 2007;3:13-7. https://doi.org/10.1007/s11306-006-0038-y.

\section{Publisher's Note}

Springer Nature remains neutral with regard to jurisdictional claims in published maps and institutional affiliations.

Submit your manuscript to a SpringerOpen ${ }^{\circ}$ journal and benefit from:

- Convenient online submission

- Rigorous peer review

- Open access: articles freely available online

- High visibility within the field

- Retaining the copyright to your article

Submit your next manuscript at $\boldsymbol{\sim}$ springeropen.com 